\title{
Improving the ability of mathematical modeling at the elementary school students through Problem-Based Learning-Based Scaffolding
}

\author{
Aryanti \\ Indonesia University of Education \\ Bandung, Indonesia
}

\begin{abstract}
The issue of the difficulties experienced by students is not a new thing. One form of student difficulties is the inability of students to solve problems that require a combination of real-life knowledge with mathematical knowledge received at school, namely the transition from the real world to the mathematical model and vice versa, transition model solution to the real world. Through Quasi-Experimental design with preposttest design, the researchers apply a problem based learningbased scaffolding in primary school students in Bandung, as an effort to improve students mathematical modeling capabilities. The number of students in the experimental group is as many as 89 students and the control group was 102 students. The results showed that the average value of the gain of the experimental group of 0.36 , while the control group of 0,137 . Differences in the distribution of both groups gain value, is seen in the medium category and low category. ANOVA test results showed that a large value of $F$ is $\mathbf{2 2 2 . 6 7 7}$, indicates that there is the effect of problem-based learning-based scaffolding to increase the ability of mathematical modeling at the elementary school students .
\end{abstract}

Keywords- problem-based learning, mathematical modeling, elementary students

\section{INTRODUCTION}

The problem of mathematical modeling in elementary school (SD) is often debated by educational experts about the urgency of context modeling at the primary level. However, [1] believed that modeling of mathematics and its applications can start at the primary school level. [2] says that some kind of "word problems" is a pretty good workout for a mathematical modeling. This means that the construction of elementary mathematical modeling becomes important enough to be mastered by the student in accordance with the level of depth of the problem and the characteristics of himself. In addition, mathematical modeling is also strongly associated with the concept of learning math in elementary school. [3] states that there are two core components of mathematics should be taught in elementary school that is "Standards for Mathematical Practice and Standards for Mathematical Content". The first type describes the mathematics that would produce a meaningful learning and help students understand math in accordance with the cognitive development. While the second type is associated with an outline of the concepts and skills that must be learned in each class. The position of mathematical modeling is able to create a condition that provides substantial opportunities to achieve an understanding of the students in the two components.
In mathematical modeling, the students developed a mathematical process such as describing, explaining, predicting, representing and organizing the data [4]. Furthermore argued that mathematical modeling is a process "a mathematical representation" of concepts and relationships in a phenomenon that can be used to clarify the understanding and use to solve problems. It is further mentioned that the act of mathematical modeling, not only includes representation but also "take action" on the representation and interpret the meaning of a person's actions in the mathematical model, and the phenomena being modeled.

Some researchers have found a number of conditions that are formed when a student is involved in mathematical modeling activity. For example, students need to identify the problem and its relation and describe the situation of mathematics [5] students fully involved in the cycle of mathematical modeling to test the initial model in a particular context, then revise and generalize the model by placing it in a different context ([6]; [7]). That the purpose of mathematical modeling to develop procedural and abstract skills with conceptual understanding as a result of the modeling process and the involvement of students with problems ([7]; [8]). The above results illustrate that the students are challenged to develop the ability to think of mathematics, namely the ability to explain, to connect, to change and to generalize information, where such conditions lead students to be directly involved in a process of mathematical, such as quantifying, dimensioning, coordinating, categorizing, algebraizing, and systematizing relevant objects, relationships, actions, patterns, and regularities. The context is a process of mathematical thinking. In addition, mathematical modeling also helps students perform externalization understanding of the situation that was built by the model through the conceptualization of ideas and mathematical processes [7]

Based on the above, this research seeks to provide academic studies in an effort to improve the ability of mathematical modeling in primary school students by applying the model of Problem Based Learning (PBL) -based Scaffolding. Research on PBL had been carried out, but on a certain side showed some researchers have questioned the effectiveness and efficiency of PBL. For example, responsibility and autonomy experienced by students can be unstructured, chaotic and even stress [9]. [10] found PBL approach can lead to ineffectiveness of cognitive resources are already limited, and thus, are not optimally designed for 
learning. Furthermore, in solving "complex problem" without any prior knowledge of the procedure the solution can provide a high load on the memory.

While scaffolding strategy is based on Vygotsky's theory. According to Vygotsky, that learning occurs when children are working or studying completing tasks that have not been studied, but the tasks were still within the range of capabilities they have or those tasks are in the area Zone of Proximal Development, as the potential development of capabilities higher than a person's state of progress at the moment. Vygotsky believed that 'higher mental functions "will appear in a process of conversation or collaboration among individuals before the higher mental functions were absorbed into the individual. There are two major implications of Vygotsky's theory in education. First, is the need for the class structure and form of cooperative learning among the students, so that students can interact around difficult tasks and bring mutual problem-solving strategies are effective in each of their Zone of Proximal Development. Second, the approach to teaching emphasizes Vygotsky scaffolding (limited guardianship) and construction is expected is the longer students more responsible for their own learning. In summary, according to Vygotsky, students need to learn and work in groups so that students can interact with each other and needed the help of the student teachers in learning activities.

\section{METHODS}

\section{A. Design and Participants}

Research design using Quasi-Experimental type design with the pre-posttest design. Based on this type, the researchers apply a pre-and posttest design, which is divided into two study groups: a control group and experimental group. Both groups were subjected to pretests as supporting material to perform the treatment, then do post-test to know the difference between the two groups. The experimental group using PBL-based scaffolding approach to learning mathematics, while the control group using learning with conventional approaches.

Subjects were students in elementary school (SD) in Bandung from three primary schools were selected. Before the treatment is given, the whole subject of research by prior knowledge of mathematics test and the results are used for decision making in determining control class and experimental class. Consideration of researchers is to know about the homogeneity of variance. The test results showed that the statistics Lavene value of 0.088 with a significance level of 0.768. The level of significance, suggesting that both sets of data have a homogeneous variance of $0.971>0.05$. Based on the above considerations, the chosen class control and experiment randomly. The Number of subjects from the control group was 102 students, while the experimental group was 89 students.

\section{B. Instruments and Data analysis}

Data were collected through a process of pretest and posttest in both study groups (experimental and control). Pretest and post-test question contain a set of items in which there are indicators of mathematical modeling. Their indicators are: a) understand and simplify the problem, b) manipulating the problem and develop a mathematical model, c) interpreting the results of the solution, and d) verify, validate and reflect the problem solution. A number of items in pre-test consist of 4 items and post-test consists of 5 items, whole items which of the measured variables of the study. Measurement of study variables using a score of $0-4$ in each category have been determined under the rubric and scoring techniques.

Both these instruments do the testing process to test the validity and reliability of the instrument. Validity test using Pearson correlation test models. While the reliability of the instruments this study refers to internal consistency reliability with the test model used was Cronbach Alpha coefficients. The post-test instrument produces Pearson correlation value is significant with a Cronbach alpha value of 0.778; Descriptive analysis of data using descriptive statistical measures such as mean, standard deviation, and curves. ANOVA test was used to test the hypothesis.

\section{Procedure}

This research procedure is a series of activities to be implemented in conducting research. These steps are as follows: (a) Determine the subject of research, (b) Make research instruments for each variable and subject matter being taught, (c) Analyze the results of trials by examining the elements of validity of the instrument, instrument reliability, (d) Choosing the experimental group and the control group, (e) Conduct learning approach "problem based learning-based scaffolding", (g) Implement posttest, and (h) Analyze the data pretest and posttest.

\section{RESULTS AND DISCUSSIONS}

Research results show that the pre-test and post-test study groups respond differently. The data in the table below shows the quantitative description about the outcome.

TABLE I. MEANS, MinimUM, AND MAXIMUM OBSERVED SCORES, AND Standard DeViation in THE MATHEMATICAL Modeling ABILITIES

\begin{tabular}{|c|c|c|c|c|c|c|}
\hline \multicolumn{2}{|c|}{ Group } & $N$ & Min & Max & Mean & Std \\
\hline control & $\begin{array}{c}\text { Pre-test score } \\
\text { (Maximum } \\
\text { score =16) }\end{array}$ & 102 & 0 & 12 & 5.18 & 3.46 \\
\cline { 2 - 7 } & $\begin{array}{c}\text { Post-test } \\
\text { score } \\
\text { (Maximum } \\
\text { score =20) }\end{array}$ & 102 & 0 & 15 & 7.02 & 3.77 \\
\cline { 2 - 7 } experiment & $\begin{array}{c}\text { Gain value } \\
\text { Pre-test score } \\
\text { (Maximum } \\
\text { score }=16)\end{array}$ & 102 & 0.176 & 0.600 & 0.361 & 0.109 \\
\cline { 2 - 7 } & $\begin{array}{c}\text { Post-test } \\
\text { score } \\
\text { (Maximum } \\
\text { score }=20)\end{array}$ & 89 & 0 & 13 & 5.65 & 3.12 \\
\cline { 2 - 7 } Gain value & 89 & 0.000 & 0.444 & 0.137 & 0.098 \\
\hline
\end{tabular}

Based on that data, indicate that the average value of the post-test in the experimental group was higher than the average value of the control group (10.72> 7.02) in which the maximum score of post-test was 20 . Then in the pre-test, the average value does not provide a significant difference (5.65> 
5.18). This context gives the meaning that both study groups start the process with initial skill level is relatively the same. Then after the occurrence of the learning process, the final value of both groups showed a significant difference. Then, the experimental group of research subjects who are at moderate and low groups, the gain of the mathematical modeling spread with almost equal amounts, but in the control group showed that almost all the subjects that are in the low category

On the movement of the value of research, subjects can be seen in the following graph

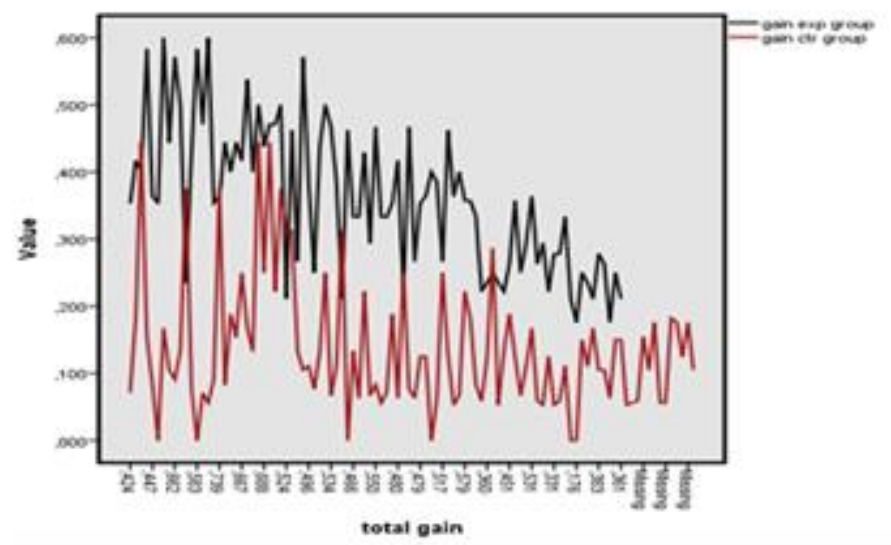

Fig. 1. The movement of the gain value of research subjects in the experimental group and the control group

The above results illustrate that the movement of the value of the gain of the experimental group with the tendency is in a higher position when compared with the control group rate movements gain. These responses indicate that the subjects in the experimental group give a higher yield, although the acquisition value of the gain in the middle category. This response is not detached from the learning process performed by the teacher through the implementation of PBL-based scaffolding. In this context, suggesting that the treatment given by the researchers gave a different response in the process of improving the ability of mathematical modeling. Description of the data on the distribution subject to the ability of mathematical modeling showed that none of the subjects in the high category. The gain is seeing an increase in research subjects before and after given treatment given, so the data illustrates that there is no subject that has increased 0.7 upwards. This condition is strongly associated with the characteristics of elementary school students and the level of difficulty of mathematical modeling so that the results obtained in this study indicate that a realistic outcome.

The results of hypothesis testing through the analysis of variance test showed the following table
TABLE II. RESULTS OF ANOVA

\begin{tabular}{|c|c|c|c|c|c|c|}
\hline Source & $\begin{array}{c}\text { Type III } \\
\text { Sum of } \\
\text { Squares }\end{array}$ & df & $\begin{array}{c}\text { Mean } \\
\text { Square }\end{array}$ & F & Sig. & $\begin{array}{c}\text { Partial } \\
\text { Eta } \\
\text { Squared }\end{array}$ \\
\hline $\begin{array}{c}\text { Corrected } \\
\text { Model }\end{array}$ & $2,389^{\mathrm{a}}$ & 1 & 2,389 & 222,677 &, 000 &, 541 \\
\hline Intercept & 11,817 & 1 & 11,817 & 1101,448 &, 000 &, 854 \\
\hline Klp_Subyek & 2,389 & 1 & 2,389 & 222,677 &, 000 &, 541 \\
\hline Error & 2,028 & 189 &, 011 & & & \\
\hline Total & 15,574 & 191 & & & & \\
\hline $\begin{array}{c}\text { Corrected } \\
\text { Total }\end{array}$ & 4,417 & 190 & & & & \\
\hline
\end{tabular}

${ }^{\text {a. }}$ a. R Squared $=, 541$ (Adjusted R Squared $=, 538$

b. b. Computed using alpha $=, 05$

This series of analysis result "one way ANOVA" in the table above illustrates that:

The results of the analysis of "homogeneity of variance" through Lavene test showed that the distribution of the data information on the mathematical modeling capability is homogeneous in accordance with the sig. 0.075> 0.05 as recommended values

The value of the F statistic at 222.677 in klp_subyek with the sig. $0.000<0.05$, which indicates that there is the influence of PBL-based scaffolding in this study to increase the ability of mathematical modeling

Effect size of the value of "partial eta squared" in klp_subyek gives an indication that the effects of treatment variables are "PBL-based scaffolding " amounted to 0.541 against the increase in mathematical modeling capabilities

The value of adjusted $\mathrm{R}$ Squared of .538 suggests that treatment variables contribute to the variability in mathematical modeling of existing ANOVA models at $53.8 \%$

Based on a whole series of these interpretations, it is concluded that the increase in the ability of the mathematical modeling of the elementary school students by learning with PBL-based scaffolding higher than students taught by the conventional approach.

\section{INTERPRETATION}

Hypothesis test results show that learning with PBL-based scaffolding a positive effect on improvement of mathematical modeling capabilities in research subjects. In the learning process that connects the math material with the ability of mathematical modeling, students undertake a process of abstraction of the real problems based on certain assumptions into mathematical symbols. Thus, the mathematical model is a mathematical translation of an idea or the idea of a real problem that is expressed through symbols or symbols of mathematics in solving problems. The forms of abstraction include quantification process, dimensions, coordination, classify, algebra, and systematization of relevant objects, relationships, actions, patterns, and regularity.

Examples of models of activities for students to reveal how students think about a real-life situation can be modeled by mathematics. As a result, students must clearly describe their thought processes and do not justify a single solution, but all (or most) optimal and appropriate solutions. The involvement 
of students with math task results in the development of mathematical concepts to develop mathematical ideas can be done through problem-solving. Thus, to develop a mathematical model of the student should be able to explain, predict, or manipulate the kind of real-life situations that are presented to them. In this way, modeling activities allow students to document their own thinking and develop learning.

In accordance with the above context, the learning problem based learning approach based scaffolding bring features a "bridge" in the process of modeling. These features include: Authentic problem situations; Problems that appear to be stressed in the context of the experience (problem) of the students so as to bring the situation motivating, interesting, and relevant to their world, and that requires a certain mathematical process. When students put their reasoning into their own authentic context, the course will provide a more meaningful answer. This requires teachers to not only provide real-world Contexts, but also the real-world solutions. PBL-based scaffolding has a component known as the stage of orientation to the problem situation (meeting the problem) that determines the stage for further investigation. Therefore, at this stage presentations must attract students and generate curiosity.

Opportunities for exploration and application models; This activity was followed by exploration models activity or activities in which students can consolidate and improve their conceptual systems that have been developed as well as building a strong system of representation for this system. At the end of the model exploration activities, students produce a strong conceptual tools or models that can be applied to other related issues. The next activity in the sequence is the task of the application model, in which a student will face a new problem in the development of conceptual tools. This new activity requires some adaptation to tools and engage students in problem posing as well as problem-solving and information gathering and processing information. PBL-based scaffolding set up a feature Problem Analysis and Learning Issues that is where the students are expected to: (a) brainstorming and analysis of the problem, (b) the identification of learning problems and formulating learning goals, (c) the task of selflearning, (d) a learning task group, and then proceed to list the matter among themselves and seek information from books, journals, Internet resources and so on, and returned with an explanation of the issues and questions

Multiple Interpretations and Approaches; Modeling activities for students involving simultaneous interpretation that must be considered in achieving the goal of modeling. Each component may be incomplete, ambiguous, or undefined; there may be too much data, or there may be a visual representation that is difficult to interpret. When presented with information that is open to more than one interpretation, the student may make an unwarranted assumption or may cause a bottleneck in the development model of the work of students (English \& Lesh, 2002). This is where the role of the interaction of group members to re-interpret the information problems. PBL prepares a Discovery and Reporting, i.e. after the investigation and self-study, students who reported the findings. At this stage of students gathered to share new information that they have individually. Students practice collaboration and communication skills through questions and seek further information from the other students.

Opportunities for Social Development; The communication process inherent in modeling activities have played an important role in the social relations of students and the development of mathematics. Activity modeling is specifically designed for small groups to affect their collective responsibility to ascertain whether the models produced meets the desired criteria bermanfaaat. Many questions, conjectures, arguments, revision, and resolution arise in developing and assessing their model, as a result of the opportunity to communicate (discussion). It also develops the skills to argue and ask for justification of ideas they have. PBL provides opportun ity as possible to make the process of collaboration and communication, both within the context of discovery and reporting and in the context of the solution presentation and reflection .

Multifaceted End Products; Modeling a problem that is used for students with a number of criteria that must be met in producing their final model. These criteria not only guide in the process of modeling but also constructing "assessment model", both during and after the construction of the model. That is, students are more able to assess their products, identify gaps, and then revise and refine their models. Or, if some alternative models considered at the same time, the students are able to assess the strengths and weaknesses of each. on this side, the PBL-based scaffolding gives this stage where students can reflect on that when the student presents a solution to the "problem scenarios" involving contextualization and application of knowledge to the situation.

Opportunities for Optimal Mathematical Development; In mathematical modeling, students are involved in an important mathematical process as including explaining, analyzing, coordinating, explain, construct, critical reasoning, and create mathematical symbols, relationships, patterns, or rules relating to the modeled system. This means that there is an opportunity to develop the math skills of the students. PBL-based scaffolding provides the opportunity for students to integrate knowledge from different disciplines and sources in synthesizing ideas. At this stage, students are encouraged to summarize and integrate key principles and concepts of mathematics so that the ability to analyze, coordinate, explaining, constructing, critical reasoning, and create mathematical symbols, relationships, patterns, or rules relating to the modeled system became integrated.

The above description provides an overview of the process of mathematical modeling in learning through PBL-based scaffolding, which essentially shows that mathematical modeling capability can be developed through a PBL-based scaffolding for their features that are integrated with each other.

The results showed that the learning process in the experimental group was able to improve the mathematical modeling capabilities through a set of instructions given by the teacher. Exercise and limited guidance are able to provide a large enough space in the process of resolving cases based problem-solving. [11] stated that the process of mathematical modeling to provide enough space for students to develop their 
creativity, encouraging their learning activities such as experiments or investigations that lead to a conjecture gives a pretty strong desire for students to explore and investigate mathematics. On this side, the PBL-based scaffolding can develop these skills by the features contained in the approach. Several studies on the use of PBL results, among others, to encourage the development of skills of reasoning ability [12], was able to develop problem-solving skills [13]. In the context of the relationship with mathematical modeling, this study is consistent with results of research [14] who found that an increase in the ability of the mathematical modeling of the student teachers through ethnomathematics SD-based contextual learning

\section{CONCLUSION}

Based on the research that has been done, the conclusion that the implementation of Problem based Learning (PBL) scaffolding based on elementary school students are able to provide increased capacity with the mathematical modeling of the effect size value of 0541. This quantity is supported by the value of Adjusted R Squared produced a model of 0.538 which means that $53.8 \%$ of the variance in mathematical modeling capabilities are described by giving treatment.

\section{ACKNOWLEDGMENTS}

This article is part of a doctoral dissertation research at the Indonesia University of Education. Gratitude to the heads and teachers of the elementary school where this research carried out. We realize that without the help of these parties, it is difficult to research carried out well.

\section{REFERENCES}

[1] Greer, B., Verschaffel, L., \& Mukhopadhyay, S. (2007). Modelling for life: Mathematics and children's experience. In Modelling and applications in mathematics education (pp. 89-98). Springer US. (2007)

[2] Verschaffel, L. Taking the modeling perspective seriously at the elementary school level: promises and pitfalls. In A. Cockburn \& E. Nardi (Eds.), Proceedings of 26th Annual Meeting of the International
Group for the Psychology of Mathematics Education (Vol. 1, pp. 64 80). Norwich: University of East Anglia. (2002)

[3] Curran, Reggie. (2013) Helping Children Learn In The Primary And Elementary Years Math. A Guide To The Math Common Core State Standards For Parents And Students (Brochure) by. Tennessee State Personnel Development Grant. Tersedia di: www.TNCORE.org

[4] National Council of Teachers of Mathematics (2000). Principles and standards for school mathematics. Reston, VA: Author

[5] Mousoulides, N.; Pittalis, M. \& Christou, C. (2006). Improving Mathematical Knowledge Through Modeling In Elementary Schools. In Novotná, J., Moraová, H., Krátká, M. \& Stehlíková, N. (Eds.). Proceedings 30th Conference of the International Group for the Psychology of Mathematics Education, Vol. 4, pp. 201-208. Prague: PME. 4 - 201

[6] English, L (2003). Mathematical Modelling With Young Learners. In Susan J. Lamon; Willard A. Parker; Ken Houston (eds). Mathematical Modelling: A Way Of Life. Horwood Publishing Chichester. England

[7] Lesh, R., \& Doerr, H. M. (2003). Beyond Constructivism: A Models and Modeling Perspective on Mathematics Problem Solving, Learning, and Teaching. Hillsdale, NJ: Lawrence Erlbaum

[8] Lesh, R., Cramer, K., Doerr, H. M., Post, T., \& Zawojewski, J. (2003). Model development sequences. In H. M. Doerr \& R. Lesh (Eds.), Beyond constructivism: A models \& modeling perspective on mathematics problem solving, learning \& teaching (pp. 35-58). Hillsdale, NJ: Lawrence Erlbaum Associates, Inc.

[9] Sierens, E., Soenens, B., Vansteenkiste, M., Goossens, L., \& Dochy, F. (2006). The authoritative teaching style: a model for the study of teaching styles Pedagogische Studien, 83, 419-431

[10] Kirschner, P. A., Sweller, J., \& Clark, R. E. (2006). Why minimal guidance during instruction does not work: an analysis of the failure of constructivist, discovery,problem-based, experiential, and inquiry-based teaching. $\quad$ Educational $\quad$ Psychologist,41, 75-86. http://dx.doi.org/10.1207/s15326985sep4102_1.

[11] Turmudi. (2009). Mathematical Modelling (Mathematical Modeling) Based Realistic in middle and high school. Summary of Results of UPI Bandung

[12] Hmelo, C. E., Guzdial, M., \& Turms, J. (1998). Computer-support for collaborative learning: Learning to support student engagement. Journal of Interactive Learning Research, 9, 107-129

[13] Gallagher, S. A., Stepien, W. J., \& Rosenthal, H. (1992). The effects of problem-based learning on problem-solving. Gifted Child Quarterly, 36, 195-200.

[14] Supriadi, Suryadi, D., Sumarmo, U., Rakhmat, C. (2014). Developing Mathematical Modeling Ability Students Elementary School Teache Education through Ethnomathematics-Based Contextual Learning. 